\title{
LETTERS
}

\section{Opioid warning label}

The 2017 Canadian "Guideline for Opioid Therapy and Chronic Noncancer Pain"1 may be a helpful step in dealing with Canada's opioid crisis, but additional policies also must be implemented. As a physician treating addiction, I feel that all prescriptions for opioids should have the following label attached: "THIS OPIOID MAY CAUSE ADDICTION."

This label would compare with the warning labels provided on each cigarette package that is sold in Canada. These warning labels for cigarettes were opposed by the tobacco industry; I feel that the pharmaceutical industry and many pharmacists will oppose similar labelling.

However, Canada's opioid crisis demands that a similar type of warning label be used.

\section{Melvin Herzog MD}

Family Physician, Toronto, Ont.

Cite as: CMAJ 2017 October 23;189:E1318. doi: $10.1503 / \mathrm{cmaj} .733320$

\section{Reference}

1. Busse JW, Craigie S, Juurlink DN, et al. Guideline for opioid therapy and chronic noncancer pain. CMAJ 2017;189:E659-66.

Competing interests: Melvin Herzog is a family physician involved mainly in treatment for opioid addiction in Toronto. 